\title{
INFLUENCE OF DIFFERENT UNIVERSAL ADHESIVES ON FRACTURE RESISTANCE OF ENDODONTICALLY TREATED TEETH
}

\author{
Tamer Mohamed Elshehawy"
}

\begin{abstract}
Objective: To examine the influence of different universal adhesives on fracture resistance of endodontically restored teeth.

Materials and Methods: Fifty sound maxillary premolars were collected. MOD cavity and root canal treatment were performed in 40 teeth only. The width of the cavity was one-third of the inter-cuspal distance at the occlusal portion and one-third of the bucco-lingual width of proximal boxes. The floor of the cavity was coronally prepared by $1 \mathrm{~mm}$ to the CEJ. The cavo-surface margins were prepared at a butt joint. All samples were assorted into five equal groups $(\mathrm{N}=10)$ : group I: intact teeth (+ve control), group II: prepared unrestored (-ve control), groups III, IV, and V: these groups had root canal treatment and standardized MOD cavities then restored with final resin composite restorations (Filtek Z350 XT) by using three types of adhesive systems; Single Bond Universal, All-Bond Universal and Tetric N-Bond Universal, respectively. The teeth were mounted to universal testing machine and subjected to compressive load at crosshead speed $0.5 \mathrm{~mm} / \mathrm{min}$. Fracture modes were evaluated under a stereomicroscope at magnification of 12X. Statistical analysis was performed using SPSS, version 20.0.
\end{abstract}

Results: There was significant improvement in fracture resistance in restored teeth (group III, IV and V) than unrestored teeth (group II), but didn't reach the fracture resistance of sound teeth (group I). There was no significant difference between restored groups.

Conclusions: According to the limitations of this study, resin composite restoration of endodontically treated teeth using different universal adhesives improve fracture resistance of these teeth.

KEYWORDS: Universal adhesive, Endodontically treated teeth, Fracture resistance, Fracture mode.

* Lecturer, Operative Dentistry Department, Faculty of Dentistry, Mansoura University, Egypt. 


\section{INTRODUCTION}

Teeth fracture is a common dental problem, it considered the third cause of tooth loss after periodontal disease and caries.(1) Tooth anatomy and cavity preparation are among many other factors contributing to cuspal fracture. The anatomy of premolars teeth makes them more prone to fracture during mastication, whereas sound teeth are rarely fracture under normal masticatory function. Many studies have emphasized the importance of conservation of tooth structure to preserve the strength of remaining tooth. ${ }^{(2,3)}$ It has been shown that premolar teeth with large intracoronal MOD preparation have reduced cusp stiffness to one-third of sound teeth due to the loss of marginal ridges and microfractures caused by applied occlusal forces. ${ }^{(4)}$

Endodontically treated teeth are structurally compromised due to loss of structure caused by caries, wear, fractures and excessive removal of dentin during root canal treatment. These teeth are reduced in strength and increased cuspal fracture under occlusal load. ${ }^{(5)}$ The weakened teeth have to be restored with a proper restoration to strengthen the remaining teeth structure. Wherefore, survival of endodontically treated teeth depends not only on satisfactory root canal treatment but also on adequate coronal restoration. ${ }^{(6)}$

The prepared teeth can be strengthened by using bonded restoration. The adhesive nature of composite has the ability to bind the cusps and decrease flexion, which is the main cause of fractures in teeth restored with amalgam. Furthermore, composite has a lower elastic modulus than amalgam, therefore, more load is absorbed within the composite. Composite may transmit lesser load to the underlying tooth structure, for this reason, and with an increase in esthetic need and the development of adhesive techniques, resin composite has become the material of choice for posterior tooth restoration.$^{(7-9)}$

Adhesive and composite are playing a valuable role in restoration of endodontically treated teeth. (10) Different adhesive systems are introduced for bonding to tooth structures. Two or three steps etchand-rinse (E\&R) systems have separate phosphoric acid etching step. In three steps E\&R primer and adhesive are applied separately. To simplify this method, the primer and adhesive resin are combined to form one solution in two step technique. These systems are technique sensitive and time consuming due to multiple steps; etching, rinsing and drying steps. ${ }^{(11)}$

Less technique sensitivity and time saving considered the main advantages of SE adhesives. ${ }^{(11)} \mathrm{SE}$ systems consist of two bottles; one of them contain etchant and primer, the other contain adhesive resin. ${ }^{(12)}$ The two bottles are mixed together in one bottle to produce single bottle SE adhesive to reduce application steps. ${ }^{(13)}$

The E\&R systems are used to remove of smear layer which provided micromechanically interlocked between bonding monomers and created microporosities that obtained micromechanical retention. ${ }^{(14)}$ The bonding mechanism of SE adhesive systems has two mechanisms. First, micromechanical bonding which resists mechanical load. Second, chemical bonding that decreases hydrolytic degradation and improve marginal seal of restoration. Both mechanisms enhance restoration durability. ${ }^{(15)}$ SE adhesives have combination of base resin monomers and functional monomers. ${ }^{(16)}$

The bonding effectiveness of SE adhesives to dentin is better than that of enamel. Pre etching of enamel surface by phosphoric acid in E\&R adhesives improves bond durability and clinical performance. The poor bond durability of SE adhesives to enamel may be due to the high hydrophilic nature of acidic monomers in SE adhesives. ${ }^{(17-19)}$ It is documented that restoration of teeth by adhesive restoration improve fracture resistance of teeth. ${ }^{(9)}$ Even with adhesive restoration in large cavity, cusp coverage is still necessary. ${ }^{(3)}$

Universal or multimode adhesive has been introduced for patient care, which may be considered as 
one-step SE adhesive. Universal adhesives can be used on a wide range of substrates such as enamel, dentin, silica-based glass ceramics, zirconia ceramics, and metal alloys, without individual pretreatment. ${ }^{(20,21)}$ Universal adhesives can be used for repair of resin composite restorations. ${ }^{(22)}$ It can be used with or without acid etching. ${ }^{(23)}$

Therefore, this study aimed to compare the fracture resistance of endodontically treated teeth when restored by resin composite using different universal adhesives in self-etch mode.

\section{MATERIALS AND METHODS}

\section{Materials}

Three different universal adhesive resin and a nanofilled resin composite were used in this study. Detail description of materials and its composition is shown in (table 1)

\section{Method}

\section{Teeth selection and Specimen preparation}

In this study fifty sound human maxillary premolars extracted for orthodontic reasons were collected. Stereomicroscope (SZ-PT; Olympus, Japan) was used to ensure that teeth were free of defects or cracks. Chloramines solution was used in concentration of $0.5 \%$ to disinfect the collected teeth for one day. The disinfected teeth were cleaned thoroughly, pumiced, washed then stored in distilled water at $37 \pm 1^{\circ} \mathrm{C}$ in incubator (BTC, Model: BT1020, Egypt) for one month. All the teeth were vertically mounted in the center of PVC (polyvinyle chloride) rings of $2 \times 2 \mathrm{~cm}$ size using an acrylic resin (Acrostone Cairo, Egypt) and fixed to $1 \mathrm{~mm}$ below the CEJ.

\section{Cavity preparation}

A standardized MOD cavity was prepared in forty teeth using straight fissure diamond instrument (No.6836 KR 314 018; Komet, Brasseler, Lemgo, Germany) in high speed handpiece. Every five preparations, a new diamond instrument was changed to warrant high cutting efficiency. The dimensions of the cavity preparation were without proximal steps buccolingual width of each cavity was one-third of the intercuspal distance at the occlusal portion and one-third of the bucco-lingual width of proximal boxes. The floor of the cavity was coronally prepared by $1 \mathrm{~mm}$ to the CEJ. The cavosurface angles of the cavity was prepared at a butt joint. All sharp line angles were rounded as showen in figure (1-a). The remaining 10 premolar will act as a control (with no cavity).

TABLE (1) Material used in the study.

\begin{tabular}{|l|l|l|l|}
\hline Material & Composition & Manufacture & Patch no. \\
\hline Single Bond Universal & $\begin{array}{l}\text { Bis-GMA, HEMA, UDMA, MDP } \\
\text { dimethacrylate, ethanol, water, silane, }\end{array}$ & 3M ESPE st.Paule, MN, USA & 608235 \\
\hline All-Bond Universal & $\begin{array}{l}\text { MDP, Bis-GMA, HEMA, Ethanol, } \\
\text { water }\end{array}$ & $\begin{array}{l}\text { ABU BISCO Inc. } \\
\text { Schaumburg, IL,USA }\end{array}$ & 1600000270 \\
\hline Tetric N-Bond Universal & MDP, MCAP,ethanol, water, silicon & $\begin{array}{l}\text { Ivoclar Vivadent AGSchaan } \\
\text { Liechtenstien }\end{array}$ & V13118 \\
\hline Filtek Z350 XT & $\begin{array}{l}\text { Filler: zircon, silicate Bis-GMA, Bis-EMA, } \\
\text { Matrix: BMAPE st.Paule, MN, USA } \\
\text { TEGDMA, UDMA,PEGDMA }\end{array}$ & N663673 \\
\hline
\end{tabular}




\section{Root canal treatment}

An access cavity was prepared, and canal orifices were enlarged with Gates Glidden drills. The root canals were instrumented initially with \#10 and \#15 k-files (MANI Inc, Tochigi, Japan), then with rotary RaCe NI-TI system (FKG Dentaire SA, cret-de-locie, Switzerland) by technique of crown down. The canals were clinically instrumented till size \#35.04 taper for standardization purposes. The canals were irrigated and cleaned by using $3 \mathrm{ml}$ of $2.5 \% \mathrm{NaOCL}$ solution with 27-gauge endodontic needle after the use of each instrument. After canals dryness, the canals were obturated with gutta-percha points (META Biomed, Korea) using resin based sealer ADSEAL (Metabiomed OK, Chungbuk, Korea) with a cold lateral condensation technique.

\section{Restoration of teeth}

All teeth were divided into Five groups $(\mathrm{N}=$
10): Group I: Sound teeth(+ve control), Group II: prepared not restored (-ve control), Group III, IV and V was restored by Filtek Z350 XT resin composite using different universal adhesives in self etch mode; Single bond universal, All bond universal and Tetric N- Bond universal, respectively. The adhesive was applied on cavity surface with agitation for $10 \mathrm{~s}$ then air-dried for $5 \mathrm{~s}$ with gentil oil/water free air stream then light cure for $10 \mathrm{~s}$ by light emitting diode device at an intensity of 1000 $\mathrm{mw} / \mathrm{cm}^{2}$ (Elipar Deep Cure; $3 \mathrm{M}$ ESPE) and the intensity was monitored by radiometer (Demetron LC, Kerr, Germany)., according to manufacture instruction. The teeth were built and filled with a nanohybrid resin composite Filtek Z350 XT. The whole cavity was incrementally restored with the procedure of centripatel technique, finishing and polishing by Enhance polishing kit (DENTSPLYSirona, USA) as showed in figure (1-b).
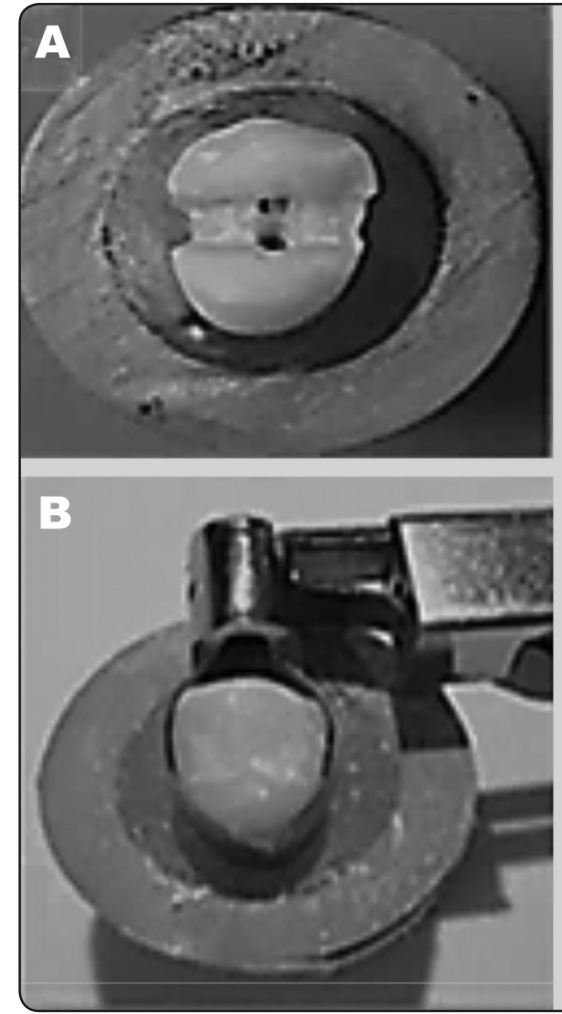
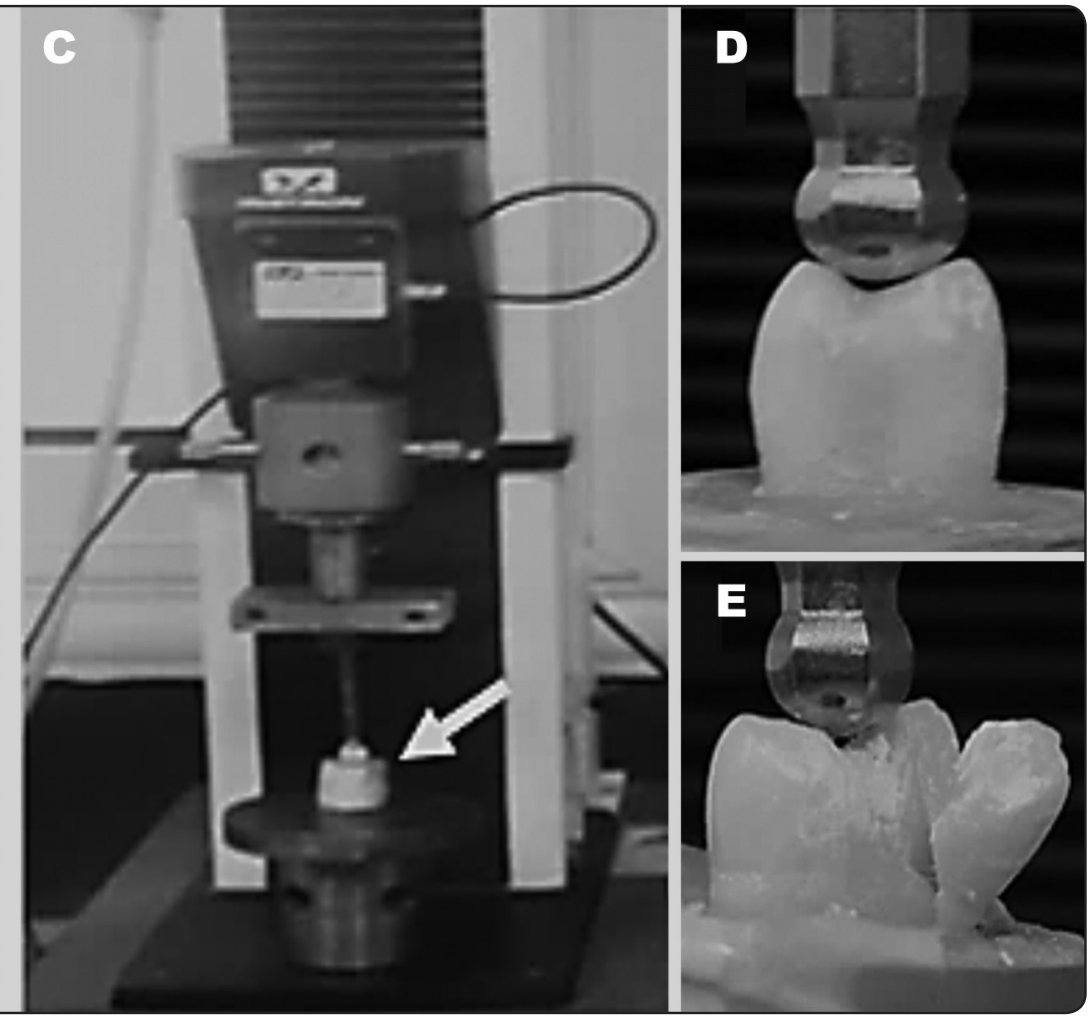

Fig. (1) : Experiment steps. a; Cavity preparation, b; composite restoration, c,d; specimen mounted on the instron (white arrow), e; fracture specimen 


\section{Fracture resistance test}

All specimens were mounted on a universal testing machine (Instron model 3345, UK) and a vertical compressive force was applied to the cusp slopes by ball tip $5 \mathrm{~mm}$ in radius, at a cross-head speed of $0.5 \mathrm{~mm} / \mathrm{min}$ till fracture of specimen. The fracture resistance was calculated in newton as showed in figure (1-c-d).

\section{6. fracture mode analysis}

All fractured teeth were examined using stereomicroscope to determine the fracture mode at magnification of 12X (Olympus, SZ61, Tokyo, Japan). Fracture modes were classified according to the following categories:

- Mode I: adhesive fracture at the interface between the tooth and the restoration

- Mode II: cohesive fracture of the tooth structure

- Mode III: cohesive failure of the restorative material

- Mode IV: Mixed adhesive and cohesive failure

\section{Statistical analysis}

One-way ANOVA used for comparing variables affecting mean values, followed by Duncan test to detect significance between groups as effect of adhesive system. Statistical analysis was performed using statistical package for the social sciences software for Windows, version 20.0 (SPSS Inc., Chicago, Illinois, USA).

\section{RESULTS}

\section{Fracture resistance}

The results of one way ANOVA are presented in table (2), Means of all groups and standard deviations and results of post hock test are presented in table (3) and figure (2).

By using one way ANOVA and Duncan post hock test, it was found that the mean value of fracture resistance load of group I (intact teeth) recorded the highest significant fracture resistance $(1025.63 \pm 84.87 \mathrm{~N})$ at $(\mathrm{P} \leq 0.05)$. Although group II (prepared, unrestored teeth) recorded the lowest significant fracture resistance $(484.16 \pm 40.70 \mathrm{~N})$ at $(\mathrm{P} \leq 0.05)$.

Meanwhile, the mean values (in Newton) of fracture resistance of cavities restored with Filtek Z350 XT with different adhesive systems, Single bond universal, All bond universal, and Tetric $\mathrm{N}$ bond recorded 899.54 $\pm 76.37,905.80 \pm 49.65$, and $\mathbf{8 5 8 . 0 6} \pm 53.64 \mathrm{~N}$, respectively, and according to Duncan test the differences were statistically not significant at $(P<0.05$.

\section{Fracture mode}

The results of fracture mode after examination under stereomicroscope were as showen in table(4) and Figure (3)

TABLE (2): One Way ANOVA

\begin{tabular}{|c|c|c|c|c|c|}
\hline & Sum of Squares & Degree of Freedom & Mean Square & F & Significance \\
\hline Between Groups & 1696857.245 & 4 & 424214.311 & 105.874 & 0.000 \\
\hline Within Groups & 180304.627 & 45 & 4006.769 & & \\
\hline Total & 1877161.872 & 49 & & & \\
\hline
\end{tabular}


TABLE (3): Mean values \pm standard deviation (SD) and Duncan test

\begin{tabular}{|c|c|c|}
\hline Group & Description & Mean values $\pm(\mathrm{SD})$ \\
\hline Group I & +ve control & $1025.63 \pm 84.87^{c}$ \\
\hline Group II & -ve control & $484.16 \pm 40.70^{a}$ \\
\hline Group III & Single Bond Universal group & $899.54 \pm 76.37^{b}$ \\
\hline Group IV & All-Bond Universal group & $905.80 \pm 49.65^{b}$ \\
\hline Group V & Tetric N- Bond Universal group & $858.06 \pm 53.64^{b}$ \\
\hline
\end{tabular}

Means with the same superscripted letters has no significant difference at $(P \leq 0.05)$.

TABLE (4): results of fracture mode

\begin{tabular}{|l|c|c|c|c|}
\hline & AD & CT & CC & MI \\
\hline Group I & $0 \%$ & $100 \%$ & $0 \%$ & $\mathbf{0 \%}$ \\
\hline Group II & $0 \%$ & $100 \%$ & $0 \%$ & $0 \%$ \\
\hline Group III & $30 \%$ & $20 \%$ & $0 \%$ & $\mathbf{5 0 \%}$ \\
\hline Group IV & $40 \%$ & $10 \%$ & $10 \%$ & $40 \%$ \\
\hline Group V & $40 \%$ & $20 \%$ & $10 \%$ & $\mathbf{3 0 \%}$ \\
\hline
\end{tabular}

AD; Adhesive failure. CT; Cohesive failure in tooth structure. CC; Cohesive failure in composite. MI; Mixed failure (adhesive and cohesive).

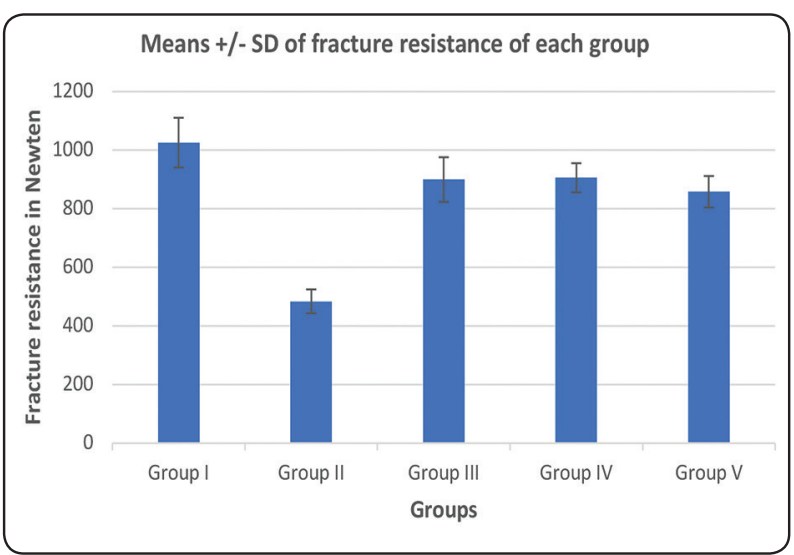

Fig. (2) :Graph showing Means +/- SD of fracture resistance of each group

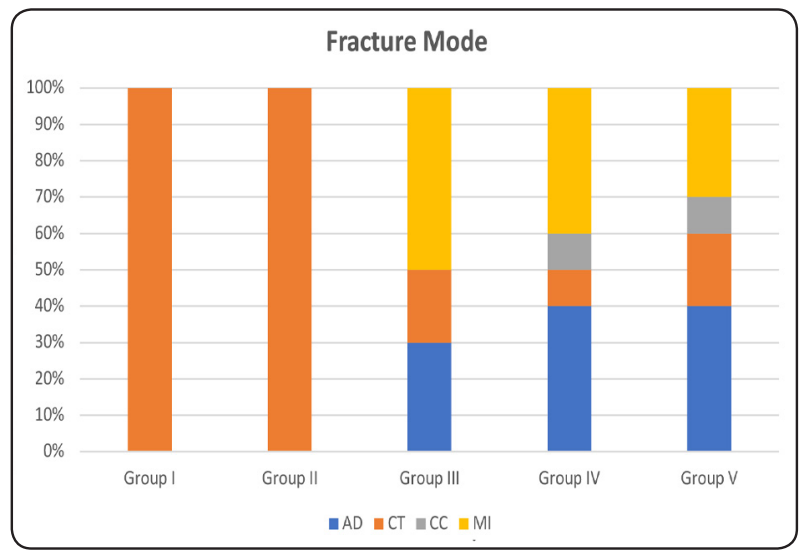

Fig. (3): graph shows fracture mode of each group 


\section{DISCUSSION}

Teeth with endodontic treatment are prone to fracture due to restorative procedures and brittleness that resulted from the extensive preparation and pulp removal. ${ }^{(24)}$ The effect of vitality loss on the physical properties of dentin have controversies. Some authors thought that the effect of vitality loss shows moderate to negligible concerning physical properties of dentin such as modulus of elasticity and microhardness. ${ }^{(25-27)}$ Whereas others approved the extensive effects. ${ }^{(24,28,29)}$ The dentinal wall thickness is critical at the root circumference. There is a direct correlation between the ability of the tooth to resist intraoral forces and the root dentin diameter. $^{(30)}$ It was established that endodontic procedures and restoration reduce rigidity of that teeth by $5 \%$ and so weaken the teeth. ${ }^{(31)}$

Among posterior teeth, specially maxillary premolars have unique morphology, position in the dental arch and cuspal inclination more susceptible to fracture under masticatory force. ${ }^{(32,33)}$ First premolar teeth were chosen in this study because the composite restoration of premolars may be considered more predictable than the molars. This concept was expected due to the lower polymerization stress caused by the smaller amount needed for composite restoration. ${ }^{(34)}$ In addition, premolars are more severe situation than molar teeth because of less crowns and dentinal surface for bonding. In this way, an extreme clinical condition was simulated. ${ }^{(34)}$

Compound (OD or OM) and complex (MOD) cavities reduce fracture resistance of teeth by $46 \%$ and $63 \%$, respectively. ${ }^{(35)}$ Other authors stated that sound premolars has fracture strength double that of unrestored MOD cavity. ${ }^{(36-38)}$ MOD cavities were designed in this study to mimic a clinical situation that may be seen in the clinic. The same situations have also been reproduced in other clinical studies. $(33,39)$ MOD cavities were prepared in specimens of this study because it has shown that cusp strength is reduced in this type of preparation. ${ }^{(2)}$
Each specimen was mounted on universal testing machine and subjected to compressive load in axial direction at crosshead speed $0.5 \mathrm{~mm} / \mathrm{min}$. This low speed produce greater plastic deformation and, so record high fracture resistance results. (36) The force direction was designed to simulate intra-oral condition. ${ }^{(40)}$ This direction distributes stresses evenly between residual tooth structure and restoration simulating a physiologic occlusion. ${ }^{(41)}$

Dentist usually use either E\&R or SE adhesives till the introduction of universal adhesive which consist of one-bottle that may be used in SE mode or with phosphoric acid pre-etching in E\&R mode or with selective enamel etching in selective etch mode. When universal adhesives are applied in full SE mode, they are basically one-step SE adhesives. In this study three universal adhesive were used in SE mode in order to simplify the procedure. As the dentin is the dominant structure in the prepared MOD cavity which gives better bond in SE mode. ${ }^{(42,43)}$

In the present in-vitro study, the strength of prepared unrestored premolar teeth (group II) was significantly lower than the intact teeth (group I) and all the remaining groups as well. This is similar to the previous findings which reported that the sound teeth have higher fracture resistance due to the rigidity and the integrity of the tooth structure. Also, the isthmus width and pulpal depth of MOD preparation are important factors that reduce fracture resistance of teeth. ${ }^{(44)}$

In the restored teeth, the composite rigidity (elastic modulus) would improve the fracture resistance. ${ }^{(45)}$ These results agree with those of El Gezawi and Al Harbi (7), Hamouda and Shehata ${ }^{(46)}$, and Zamboni et al. ${ }^{(47)}$ who reported that prepared unrestored specimens recorded significantly the lowest mean values of fracture resistance load between all the experimental groups including intact teeth and restored specimens.

Commonly used functional monomers in commercial self-etching adhesives are phosphate 
monomers, such as 10-MDP, 4-methacryloxyethyl trimellitic acid or and 2-methacryloxyethyl phenyl hydrogen phosphate. These monomers have been used as etching monomers in self-etching primers and in bonding agents to promote resin diffusion and adhesion. However, the chemical bonding potential of 10-MDP with hydroxyapatite was significantly the highest and the most hydrolytically stable ${ }^{(48,49)}$.

The evaluated adhesives in this study have $\mathrm{pH}$ range from 2.5 to 3 . The ultra-mild $\mathrm{pH}$ of these adhesives demineralize dentin partially, leaving collagen bundles supported by some hydroxyappetite crystals. Also, they contain 10-MDP monomer as a functional monomer in its composition, and bonds chemically to dentin.$^{(50,51)}$ This functional monomer forms a stable nanolayer together with a deposition of salts of MDP calcium at the adhesive interface, increasing the mechanical strength and protecting against hydrolysis. Thus, it is known that this nanolayer interacts with the substrate, resulting in "nanolayering,". Each nanolayer consists of two sublayers of parallel-oriented 10- MDP monomers, with opposite directionality. The 10- MDP methacrylate group is directed inwards, enabling mutual co-polymerization between the two opposed monomers. Its functional phosphate group is directed outwards, capturing calcium released from dentin due to the etching effect of 10-MDP. In this way, adjacent nanolayers are coupled. ${ }^{(50,52,53)}$ Another advantage of 10-MDP- was recently proposed by Amsler et al. Those authors observed that when an MDP-containing universal adhesive was added to dentin with different degrees of relative humidity or even given saliva contamination, no significant change occurs in the bond strength. The authors speculated that this insensitivity to relative humidity and saliva contamination may be due to the presence of 10-MDP. ${ }^{(54)}$

The water content in dental adhesive is essential for ionization of acidic functional monomer to etch the adherent and is directly corelated to the adhesive $\mathrm{pH} .{ }^{(55,56)} \mathrm{SE}$ adhesives with low $\mathrm{pH}$ should contain higher water. ${ }^{(57)}$ Single Bond Universal (pH $=2.7$ ) has $10 \%$ water, while All Bond Universal
$(\mathrm{pH}=3.2)$ contain less than $3 \%$ water. ${ }^{(58,59)}$ If dentin are desiccated, the water content of the adhesives is not responsible only for ionization of the acidic monomer but also rehydration of dried dentin so Single Bond Universal was capable of healing the collapsed collagen network opening interfibrillar spaces for resin infiltration. In the selfetch adhesives, the adhesives should contain water and water-soluble hydrophilic monomers, such as 2-hydroxyethyl methacrylate (HEMA), so that the acidic monomer can be ionized and penetrate into the hydrophilic dentin. ${ }^{(60)}$ Hashimoto et al. examined the effect of one-bottle SE adhesives contain water on dentin bonding. They found that bond strength of dry bonding is greater than wet bonding. ${ }^{(61)}$

Immediate bond strength was improved by the use of ethanol-wet bonding technique. Ethanol is acknowledged to be a solvent of choice when compared to water since it is able to reduce the diameter of collagen fibrils and increase the interfibrillar space, allowing monomers to easily infiltrate the collagen fibrils. ${ }^{(62)}$ This technique, called "ethanol-wet bonding technique", has been proven to efficiently seal the dentinal matrix, reducing the dentin-resin interface permeability, which would reduce the activity of collagenolytic enzymes and consequently improve bond durability to dentin substrate. ${ }^{(63)}$

So, as the three used adhesives contain 10-MDP, ethanol and water, and also they have similar $\mathrm{pH}$ range from 2.5-3, this may explain why thereis no significant differences between the used adhesives. Also, the fracture mode analysis show comparable results between the three used adhesives that may emphasis the results of fracture resistance.

\section{CONCLUSIONS}

According to the limitations of this study, restoration of endodontically treated teeth with resin composite using different universal adhesives might improve fracture resistance of these teeth. Fracture resistance of restored teeth is similar when using different universal adhesives having similar composition and $\mathrm{pH}$. 


\section{REFFERENCE}

1. Wu WC LT, Liu PR, Ramp LC, Pan YH. . In vitro compressive fracture resistance of human maxillary first premolar with different mesial occlusal distal cavity. J Dent Sci 2014;9:221-28.

2. Torabzadeh H, Ghasemi A, Dabestani A, Razmavar S. Fracture resistance of teeth restored with direct and indirect composite restorations. J Dent (Tehran) 2013;10(5): 417-25.

3. Mondelli RF, Ishikiriama SK, de Oliveira Filho O, Mondelli J. Fracture resistance of weakened teeth restored with condensable resin with and without cusp coverage. J Appl Oral Sci 2009;17(3):161-5.

4. Pradeep P, Kumar VS, Bantwal SR, Gulati GS. Fracture strength of endodontically treated premolars: An In-vitro evaluation. J Int Oral Health 2013;5(6):9-17.

5. Mannocci F, Bertelli E, Sherriff M, Watson TF, Pitt Ford T. Three-year clinical comparison of survival of endodontically treated teeth restored with either full cast coverage or with direct composite restoration. Int Endod J 2009;42(5):401-05.

6. Gillen BM, Looney SW, Gu LS, Loushine BA, Weller $\mathrm{RN}$, Loushine RJ, et al. Impact of the quality of coronal restoration versus the quality of root canal fillings on success of root canal treatment: a systematic review and meta-analysis. J Endod 2011;37(7):895-902.

7. El Gezawi AHF. Reliability of bonded MOD restorations in maxillary premolars: microleakage and cusp fracture resistance. Acta Stomatol Croat 2012;46:31-42.

8. Park J, Chang J, Ferracane J, Lee IB. How should composite be layered to reduce shrinkage stress: incremental or bulk filling? Dent Mater 2008;24(11):1501-5.

9. Soares PV, Santos-Filho PC, Martins LR, Soares CJ. Influence of restorative technique on the biomechanical behavior of endodontically treated maxillary premolars. Part I: fracture resistance and fracture mode. J Prosthet Dent 2008;99(1):30-7.

10. Gisovar FE HN, Shadman N, Shafiee L. Comparing the shear bond strength of six adhesive systems to enamel of primary teeth. . J Dent 2014;4:1-3.

11. McLeod ME, Price RB, Felix CM. Effect of configuration factor on shear bond strengths of self-etch adhesive systems to ground enamel and dentin. Oper Dent 2010; 35(1):84-93.
12. Peumans M, Munck J, Landuyt K, Lambrechts P, Meerbeek B. Three-year clinical effectiveness of a two-step self-etch adhesive in cervical lesions. Eur J Oral Sci 2005;113(6):512-18.

13. Kumari RV, Siddaraju K, Nagaraj H, Poluri RK. Evaluation of Shear Bond Strength of Newer Bonding Systems on Superficial and Deep Dentin. J Int Oral Health 2015;7(9):31-5.

14. Van Meerbeek B, De Munck J, Yoshida Y, Inoue S, Vargas $\mathrm{M}$, Vijay P, et al. Buonocore memorial lecture. Adhesion to enamel and dentin: current status and future challenges. Oper Dent 2003;28(3):215-35.

15. Van Meerbeek B, Yoshihara K, Yoshida Y, Mine A, De Munck J, Van Landuyt K. State of the art of self-etch adhesives. Dent Mater 2011;27(1):17-28.

16. Yoshida Y, Nagakane K, Fukuda R, Nakayama Y, Okazaki M, Shintani H, et al. Comparative study on adhesive performance of functional monomers. $J$ Dent Res 2004;83(6):454-58.

17. Alex G. Is total-etch dead? Evidence suggests otherwise. Compend Contin Educ Dent 2012;33(1):12-4, 16-22, 24-5; quiz 26, 38 .

18. Yazici AR, Yildirim Z, Ertan A, Ozgunaltay G, Dayangac B, Antonson SA, et al. Bond strength of one-step selfetch adhesives and their predecessors to ground versus unground enamel. Eur J Dent 2012;6(3):280-6.

19. Yazici AR, Celik C, Ozgunaltay G, Dayangac B. Bond strength of different adhesive systems to dental hard tissues. Oper Dent 2007;32(2):166-72.

20. Kim JH, Chae SY, Lee Y, Han GJ, Cho BH. Effects of multipurpose, universal adhesives on resin bonding to zirconia ceramic. Oper Dent 2015;40(1):55-62.

21. Amaral M, Belli R, Cesar PF, Valandro LF, Petschelt A, Lohbauer U. The potential of novel primers and universal adhesives to bond to zirconia. J Dent 2014;42(1):90-8.

22. Seabra B, Arantes-Oliveira S, Portugal J. Influence of multimode universal adhesives and zirconia primer application techniques on zirconia repair. J Prosthet Dent 2014;112(2):182-7.

23. Suzuki T, Takamizawa T, Barkmeier WW, Tsujimoto A, Endo H, Erickson RL, et al. Influence of Etching Mode on Enamel Bond Durability of Universal Adhesive Systems. Oper Dent 2016;41(5):520-30. 
24. Soares PV, Santos-Filho PCF, Queiroz EC, Araújo TC, Campos RE, Araújo CA, et al. Fracture resistance and stress distribution in endodontically treated maxillary premolars restored with composite resin. J Prosthodont 2008;17(2):114-19.

25. Dimitriu B, Vârlan C, Suciu I, Vârlan V, Bodnar D. Current considerations concerning endodontically treated teeth: alteration of hard dental tissues and biomechanical properties following endodontic therapy. J Med Life 2009; 2(1):60-65.

26. Shivanna V, Gopeshetti PB. Fracture resistance of endodontically treated teeth restored with composite resin reinforced with polyethylene fibres. Endodontology 2013;24:73-79.

27. Dietschi D, Duc O, Krejci I, Sadan A. Biomechanical considerations for the restoration of endodontically treated teeth: a systematic review of the literature-Part 1. Composition and micro-and macrostructure alterations. Quintessence Int 2007;38(9):733-43.

28. Mortazavi V, Fathi M, Katiraei N, Shahnaseri S, Badrian $\mathrm{H}$, Khalighinejad N. Fracture resistance of structurally compromised and normal endodontically treated teeth restored with different post systems: An in vitro study. Dent Res J 2012;9(2):185-91.

29. Sharafeddin F, Alavi AA, Zare S. Fracture resistance of structurally compromised premolar roots restored with single and accessory glass or quartz fiber posts. Dent Res J 2014;11(2):264-71

30. Hürmüzlü F, Kiremitci A, Serper A, Altundaşar E, Sİso ŞH. Fracture resistance of endodontically treated premolars restored with ormocer and packable composite. J Endod 2003;29(12):838-40.

31. Soares PV, Santos-Filho PCF, Gomide HA, Araujo CA, Martins LRM, Soares CJ. Influence of restorative technique on the biomechanical behavior of endodontically treated maxillary premolars.: Part II: Strain measurement and stress distribution. J Prosthet Dent 2008;99(2):114-22.

32. Wu M-K, Van Der Sluis L, Wesselink P. Comparison of mandibular premolars and canines with respect to their resistance to vertical root fracture. J Dent 2004;32(4): 265-68.

33. Mincik J, Urban D, Timkova S, Urban R. Fracture Resistance of Endodontically Treated Maxillary Premolars Restored by Various Direct Filling Materials: An In Vitro Study. Int J Biomater 2016;16:65-72.
34. Sengun A, Cobankara FK, Orucoglu H. Effect of a new restoration technique on fracture resistance of endodontically treated teeth. Dent Traumatol 2008; 24(2):214-19.

35. Plotino G, Buono L, Grande NM, Lamorgese V, Somma F. Fracture resistance of endodontically treated molars restored with extensive composite resin restorations. J Prosthet Dent 2008;99(3):225-32.

36. Siso Ş, Hürmüzlü F, Turgut M, Altundaşar E, Serper A, Er K. Fracture resistance of the buccal cusps of root filled maxillary premolar teeth restored with various techniques. Int Endod J 2007;40(3):161-68.

37. Kalburge V, Yakub SS, Kalburge J, Hiremath H, Chandurkar A. A comparative evaluation of fracture resistance of endodontically treated teeth, with variable marginal ridge thicknesses, restored with composite resin and composite resin reinforced with Ribbond: An in vitro study. Indian J Dent Res 2013;24(2):193-98.

38. Jiang W, Bo H, Yongchun G, LongXing N. Stress distribution in molars restored with inlays or onlays with or without endodontic treatment: a three-dimensional finite element analysis. J Prosthet Dent 2010;103(1):6-12.

39. Sagsen B, Aslan B. Effect of bonded restorations on the fracture resistance of root filled teeth. Int Endod J 2006;39(11):900-04.

40. Salameh Z, Sorrentino R, Papacchini F, Ounsi HF, Tashkandi E, Goracci C, et al. Fracture resistance and failure patterns of endodontically treated mandibular molars restored using resin composite with or without translucent glass fiber posts. J Endod 2006;32(8):752-55.

41. Sorrentino R, Salameh Z, Zarone F, Tay FR, Ferrari M. Effect of post-retained composite restoration of MOD preparations on the fracture resistance of endodontically treated teeth. J Adhes Dent 2007;9(1):49-56.

42. Peumans M, Kanumilli P, De Munck J, Van Landuyt K, Lambrechts P, Van Meerbeek B. Clinical effectiveness of contemporary adhesives: a systematic review of current clinical trials. Dent Mater 2005;21(9):864-81.

43. Breschi L, Mazzoni A, Ruggeri A, Cadenaro M, Di Lenarda R, De Stefano Dorigo E. Dental adhesion review: aging and stability of the bonded interface. Dent Mater 2008;24(1):90-101.

44. Schwendicke F, Kern M, Dorfer C, Kleemann-Lupkes J, Paris S, Blunck U. Influence of using different bonding systems and composites on the margin integrity and the 
mechanical properties of selectively excavated teeth in vitro. J Dent 2015;43(3):327-34.

45. Kikuti WY, Chaves FO, Di Hipolito V, Rodrigues FP, D'Alpino PH. Fracture resistance of teeth restored with different resin-based restorative systems. Braz Oral Res 2012;26(3):275-81.

46. Hamouda IM, Shehata SH. Fracture resistance of posterior teeth restored with modern restorative materials. J Biomed Res 2011;25(6):418-24.

47. Zamboni SC, Nogueira L, Bottino MA, Sobrinho LC, Valandro LF. The effect of mechanical loading on the cusp defection of premolars restored with direct and indirect techniques. J Contemp Dent Pract 2014;15(1):75-81.

48. Munoz MA, Luque I, Hass V, Reis A, Loguercio AD, Bombarda NH. Immediate bonding properties of universal adhesives to dentine. J Dent 2013;41(5):404-11.

49. Mena-Serrano A, Kose C, De Paula EA, Tay LY, Reis A, Loguercio AD, et al. A new universal simplified adhesive: 6-month clinical evaluation. J Esthet Restor Dent 2013;25(1):55-69.

50. Yoshihara K, Yoshida Y, Nagaoka N, Fukegawa D, Hayakawa S, Mine A, et al. Nano-controlled molecular interaction at adhesive interfaces for hard tissue reconstruction. Acta Biomater 2010;6(9):3573-82.

51. Shirai K, De Munck J, Yoshida Y, Inoue S, Lambrechts P, Suzuki K, et al. Effect of cavity configuration and aging on the bonding effectiveness of six adhesives to dentin. Dent Mater 2005;21(2):110-24.

52. Yoshida Y, Yoshihara K, Nagaoka N, Hayakawa S, Torii Y, Ogawa T, et al. Self-assembled Nano-layering at the Adhesive interface. J Dent Res 2012;91(4):376-81.

53. Fukegawa D, Hayakawa S, Yoshida Y, Suzuki K, Osaka A, Van Meerbeek B. Chemical interaction of phosphoric acid ester with hydroxyapatite. J Dent Res 2006;85(10):941-4.
54. Amsler F, Peutzfeldt A, Lussi A, Flury S. Long-Term Bond Strength of Self-Etch Adhesives to Normal and Artificially Eroded Dentin: Effect of Relative Humidity and Saliva Contamination. J Adhes Dent 2017;19(2):169-76.

55. Alex G. Universal adhesives: the next evolution in adhesive dentistry? Compend Contin Educ Dent 2015;36(1):1526; quiz 28, 40 .

56. Pashley DH, Carvalho RM. Dentine permeability and dentine adhesion. J Dent 1997;25(5):355-72.

57. Silva e Souza MH, Jr., Carneiro KG, Lobato MF, Silva e Souza Pde A, de Goes MF. Adhesive systems: important aspects related to their composition and clinical use. J Appl Oral Sci 2010;18(3):207-14.

58. Pongprueksa P, Miletic V, De Munck J, Brooks NR, Meersman F, Nies E, et al. Effect of evaporation on the shelf life of a universal adhesive. Oper Dent 2014;39(5):500-7.

59. American Association for Dental Research (AADR) \& International Association for Dental Research (IADR).Water Content (\%) of Universal Adhesives; AADR \& IADR: Alexandria, VA, USA, 2015.

60. Hanabusa M, Mine A, Kuboki T, Momoi Y, Van Ende A, Van Meerbeek B, et al. Bonding effectiveness of a new 'multi-mode' adhesive to enamel and dentine. J Dent 2012;40(6):475-84.

61. Hashimoto M, Fujita S, Kaga M, Yawaka Y. Effect of water on bonding of one-bottle self-etching adhesives. Dent Mater J 2008;27(2):172-8.

62. Tay FR, Pashley DH, Kapur RR, Carrilho MR, Hur YB, Garrett LV, et al. Bonding BisGMA to dentin--a proof of concept for hydrophobic dentin bonding. J Dent Res 2007;86(11):1034-9.

63. Shin TP, Yao X, Huenergardt R, Walker MP, Wang Y. Morphological and chemical characterization of bonding hydrophobic adhesive to dentin using ethanol wet bonding technique. Dent Mater 2009;25(8):1050-7. 